Focussed on "Crack Paths"

\title{
Investigation on fracture process of concrete
}

\author{
Sonali Bhowmik, Sandeep Dubey, Sonalisa Ray \\ Department of Civil Engineering, Indian Institute of Technology Roorkee, India-247667 \\ sonarfce@iitr.ac.in
}

ABSTRACT. A series of geometrically similar concrete beams of small, medium and large beam sizes has been tested under the action of monotonic and fatigue loading. Digital image correlation technique has been utilized to understand the fracture processes and crack growth behavior in concrete. The tip of effective crack in concrete beams under static and fatigue loading has been calculated through DIC analysis. Further, existence of size effect has been observed when the results of geometrically similar concrete beams were compared.

KEYWORDS. Digital image correlation technique; 2D DIC; Critical energy dissipation; Size effect; Fatigue.

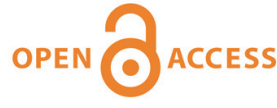

Citation: Bhowmik, S., Dubey, S., Ray, S., Investigation on fracture process of concrete, Frattura ed Integrità Strutturale, 49 (2019) 419-428.

Received: 01.12.2018

Accepted: 11.02 .2019

Published: 01.04.2019

Copyright: (C) 2019 This is an open access article under the terms of the CC-BY 4.0, which permits unrestricted use, distribution, and reproduction in any medium, provided the original author and source are credited.

\section{INTRODUCTION}

$\mathrm{M}$ ost of the civil engineering structures are subjected to repetitive loading during their service life. Under the application of load, the pre-existing randomly oriented internal cracks/defects slowly localise to form a major cracks which propagate in stable manner up to peak load. Beyond peak, the crack propagation becomes unstable leading to a softening type of behaviour. A considerable size of inelastic zone ahead of crack tip called fracture process zone (FPZ) is responsible for the exhibition of size effect in concrete like material. In heterogenous material like concrete, understanding and modelling of FPZ is complex and challenging. A precise understanding of the formation and behaviour of fracture process zone is very much important and has been attempted in the present study. Fracture energy is an important parameter and governs the fracture behavior. Calculation of fracture energy is generally done by using experimental results of monotonic loading. However, under fatigue loading determination of fatigue fracture energy is important and is lacking in the literature. The fatigue fracture energy is also defined as critical energy dissipation and is associated with the growth of macro-crack in each load cycle, which is equal to the sum of energy dissipations in all nanoscale cracks inside the fracture process zone [1]. Therefore, a thorough investigation on fracture process zone in concrete under the action of fatigue is essential for accurate estimation of critical fracture energy. Attempts have been made by various researchers to characterize FPZ in concrete by following experimental and analytical approaches. Acoustic emission (AE) technique and digital image correlation (DIC) techniques are being commonly used [2-14] now a days through which a better understanding can be achieved on the fracture process ahead of the crack tip. Different phases of fracture process zone has been studied by Mihashi et al. [2] using three-dimensional acoustic emission technique. According to the Authors, fracture process zone is developed at the peak load with an increased absorbed energy. An extension in critical crack width has been observed with the increase in width of fracture process zone. Zhang and Wu [3] have calculated the length of fracture process zone of notched concrete beams under three-point bending test through the 
analysis of load-deflection curves and acoustic emission analysis. Extension of crack has been calculated using the stiffness and $\mathrm{AE}$ record equivalence. It has been found that the size and evolution of FPZ can be determined through the difference of equivalence. Further it has been observed that the length of fracture process zone increases when the crack extension is small. Tejchman et al. [4] have investigated the properties of fracture process zone in notched concrete beams under quasi-static three-point bending test at meso-scale level. A numerical model has been used to study the strain localization phenomenon in concrete. The numerical model is further strengthened by incorporating the effect of characteristic length of micro-structure. The results obtained through the model has been compared with the results of digital image correlation method. Shah et al. [6] have investigated different fracture properties of concrete-concrete interfaces using digital image correlation technique. In their study, mode I and mode II fracture toughness and critical energy release rate have been determined using DIC technique. Different parameters such as surface displacements, strain components, crack opening and sliding displacements, load-point displacement, crack length and crack tip location have been determined through the analysis of images captured using DIC. The results obtained from the DIC analysis have been compared with the experimental results. Fracture process zone properties of concrete have been investigated by Wu et al. [15] using digital image correlation technique. In their study, it was observed that the length of FPZ increases until it is fully developed and decreases thereafter. Another study has been carried out by Skarzynski and Tejchman [16] to investigate the fracture processes in plain and reinforced concrete beam using DIC technique. Beam specimens were tested under quasi-static three-point bending test with eight concrete mixes. In addition, the effects of aggregate shape, volume, and size in concrete have been considered. Digital image correlation technique has been used to measure the surface displacement of concrete. Width of a localized zone has been found to increase with the increase in the maximum aggregate size. Ohno et al. [17] have applied acoustic emission technique on notched concrete beam specimen tested under three point bending. AE signals were analysed through Green's functions for moment tensor analysis. From the experimental results it has been confirmed that, fracture energy increases with the increase of maximum size of the aggregate. Additionally, the width of fracture process zone has been determined through results of AE source location. An increase in energy has been observed with the wider size of fracture process zone. Alam et al. $[18,19]$ have estimated crack opening and size of the fracture process zone using both digital image correlation and acoustic emission technique. DIC has been used to predict the crack opening at various stages of cracking, wherein AE technique has been used to mark the locations of crack growth due to micro/macro crack. Both the techniques have been found to be effective for the understanding of fracture processes in concrete structures. The same research group [20] in another work have addressed the effect of structural size on propagation of cracks in reinforced concrete beams using DIC technique. Trivedi et al. [21], have performed experiments on pre-notched concrete beam specimens under three-point bending. The Authors have used DIC technique and proposed a new scheme called Optical Crack Profile (OCP) to evaluate the full field of displacement and strains for visualizing the fracture growth, fracture propagation in plain concrete. The length and width of the fracture process zone are observed to be in agreement with the guideline of ACI-446 and literature study. Xie et al. [22] have conducted three-point bending tests on notched beam specimens to study the fracture behavior of fly ash based geopolymer concrete. Crack opening displacement, crack extensions and mid span deflections have been measured through DIC analysis.

\section{SPECIMEN PREPARATION AND EXPERIMENTAL DETAILS}

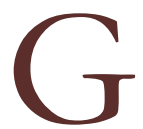

eometrically similar beams of small, medium and large size as shown in Fig. 1, have been casted using ordinary Portland cement. In the mix design, the maximum size of coarse aggregates used is $12.5 \mathrm{~mm}$. The specific gravity of fine and coarse aggregates are determined to be 2.71 and 2.62 respectively. Cube compressive strength values after 28 days of curing have been found to be $34.5 \mathrm{MPa}$. The values of modulus of elasticity and the tensile strength of concrete are $25000 \mathrm{MPa}$ and $3.5 \mathrm{MPa}$, respectively. Pre-notching has been done in the beam at the time of casting itself. The specimen dimensions have been decided according to RILEM recommendations and are provided in Table 1. The span to depth ratio S/D in each specimen has been kept equal to 4 and the width $\mathrm{B}$ is kept $50 \mathrm{~mm}$. The notch to depth ratio $\left(a_{0} / D\right)$ is kept 0.2. The schematic diagram of a typical beam has been shown in Fig. 2. Monotonic and fatigue testing have been carried out on concrete beams using $250 \mathrm{kN}$ servo-hydraulic MTS testing facility. The DIC set-up consists of a pair of digital camera and a VIC-2D software to analyses the images. During testing process, the whole specimen is illuminated by providing white light. The entire arrangement is shown in Fig. 3. Pre-notched beam specimens of small, medium and large sizes have been subjected to three point bending tests under the action of monotonic increasing load. The testing has been performed under crack mouth opening displacement (CMOD) controlled manner at an approximate rate of $0.0005 \mathrm{~mm} / \mathrm{sec}$. The CMOD measurements have been obtained using a cantilever type clip gauge placed between 
the knife edges and connected to flex test conditioner. The vertical displacement at the centre of the beam is measured by connecting a Linear Variable Displacement Transducer (LVDT) as shown in Fig. 3. The relationship between the loadCMOD and load-displacement are recorded during entire test run. After testing of specimens under static loading, fatigue tests have been performed under load control manner with sinusoidal wave form of frequency $1 \mathrm{~Hz}$ with an acquisition of load, CMOD, time, counts, stroke (displacement of the piston) data. Varying load amplitude has been considered in the present study. The minimum $\left(\mathrm{P}_{\text {min }}\right)$ and maximum loads $\left(\mathrm{P}_{\max }\right)$ for the repetitive load cycles have been kept as $0.1 \mathrm{kN}$ and $0.5 \mathrm{kN}$ respectively for first 200 load cycles. Beyond every 200 load cycles, the maximum load level is increased by $0.5 \mathrm{kN}$. The typical loading pattern is shown in Fig. 4.

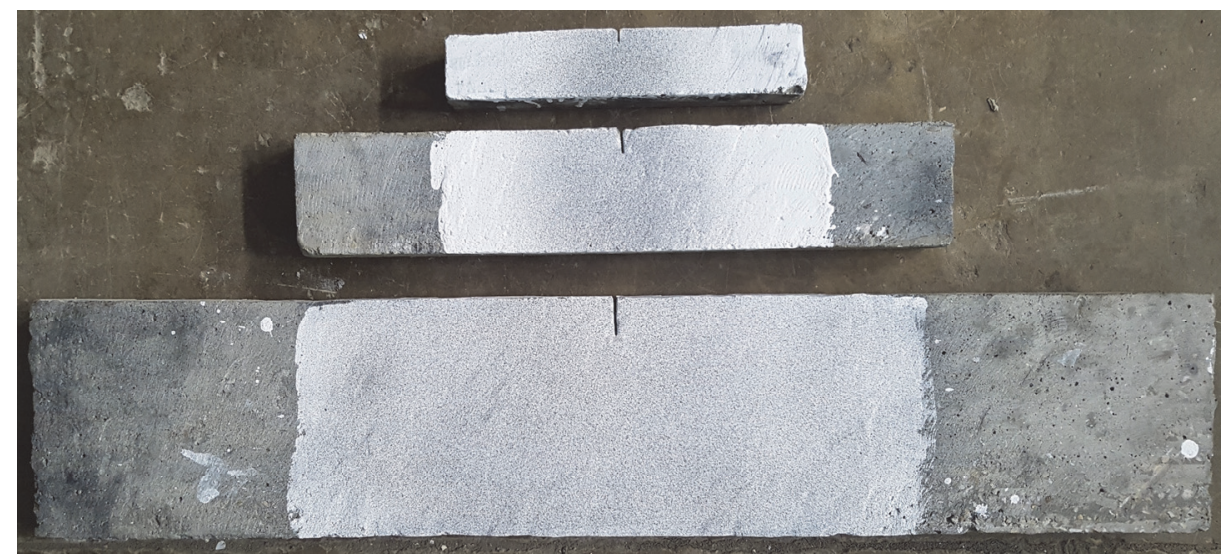

Figure 1: (a) Geometrically similar beams of small, medium and large size.

\begin{tabular}{cccccc}
\hline Specimen & $\begin{array}{c}\text { Dimensions } \\
\text { Span }(\mathrm{S})\end{array}$ & $\begin{array}{c}\text { Length }(\mathrm{L}) \\
(\mathrm{mm})\end{array}$ & $\begin{array}{c}\text { Depth }(\mathrm{D}) \\
(\mathrm{mm})\end{array}$ & $\begin{array}{c}\text { Width }(\mathrm{B}) \\
(\mathrm{mm})\end{array}$ & $\begin{array}{c}\text { Notch size } \\
\left(\mathrm{a}_{0}\right)(\mathrm{mm})\end{array}$ \\
designation & 200 & 300 & 50 & 50 & 10 \\
Small & 400 & 550 & 100 & 50 & 20 \\
Medium & 800 & 1000 & 200 & 50 & 40 \\
Large & & & & \\
\hline
\end{tabular}

Table 1: Specimen geometry of beam specimens

Experimental results of plain concrete beams of different size tested under three point bending are provided in this section.

DIC technique has been employed during the entire test period. The basic principle of DIC is that, it compares digital images of a test specimen at both deformed and undeformed stage. The surface displacement and full field 2D deformation and strain contours can be measured by tracking a collection of pixels blocks called subset with unique speckle pattern in the series of images.

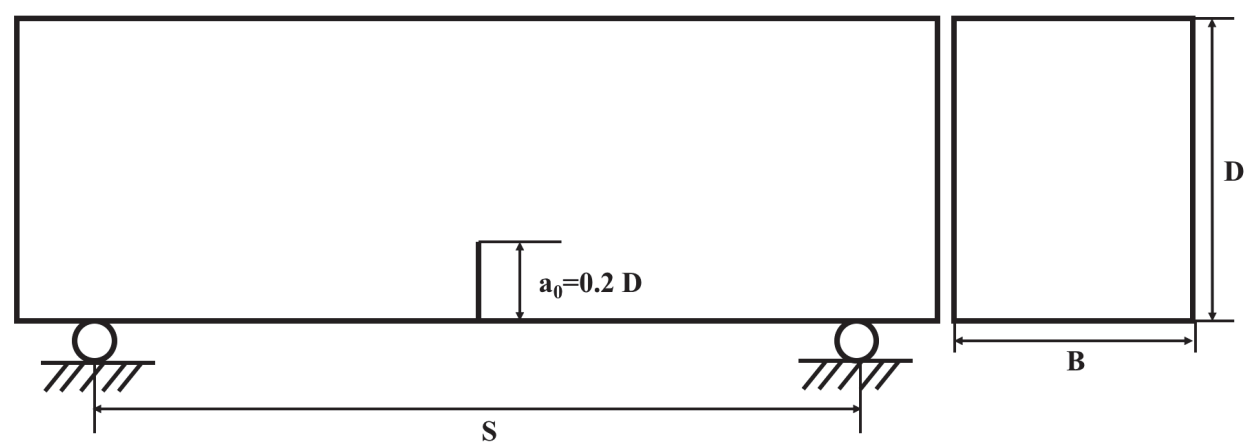

Figure 2: Schematic diagram of a beam 


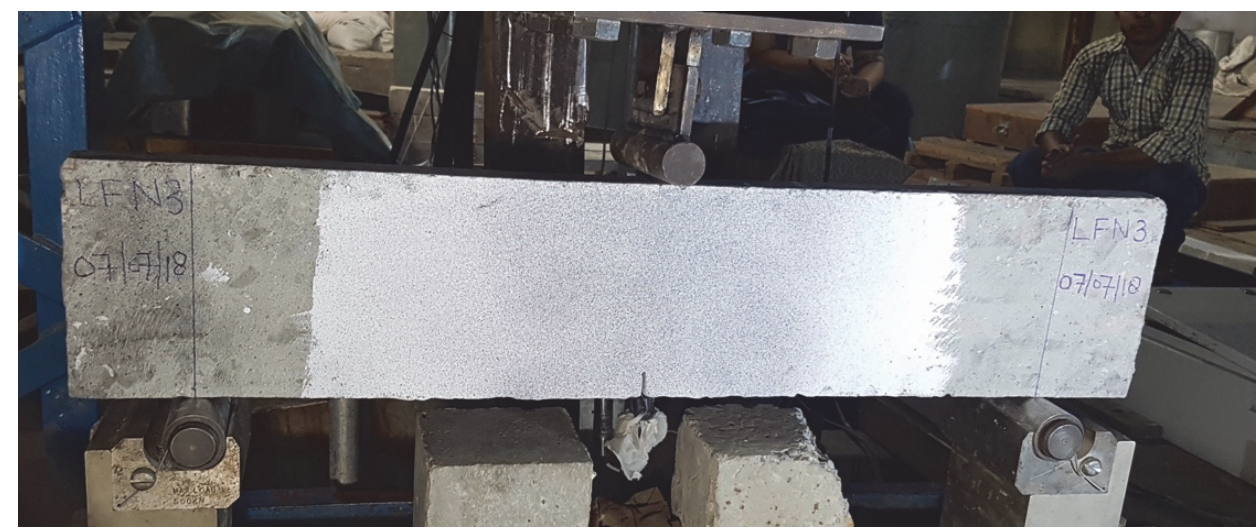

Figure 3: Fatigue test set up for three-point bending

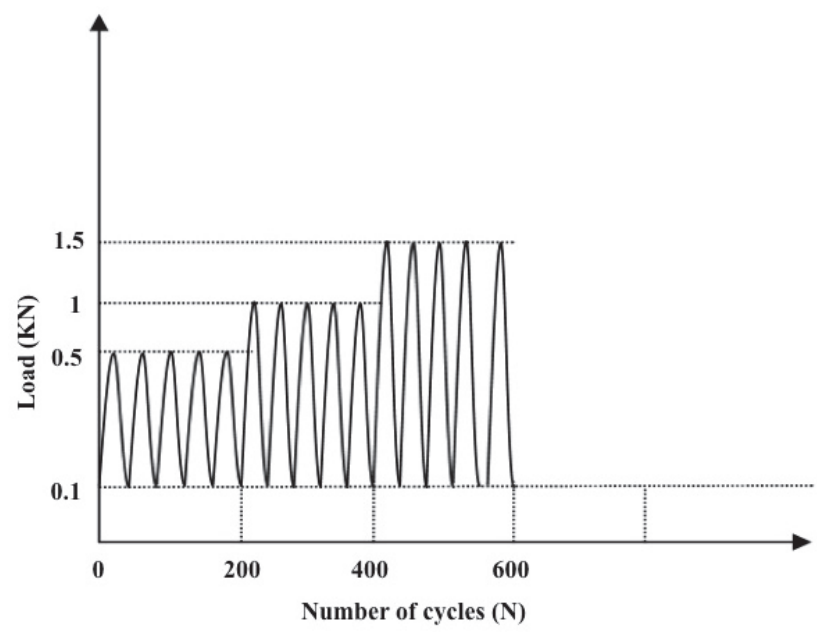

Figure 4: Loading pattern for fatigue testing

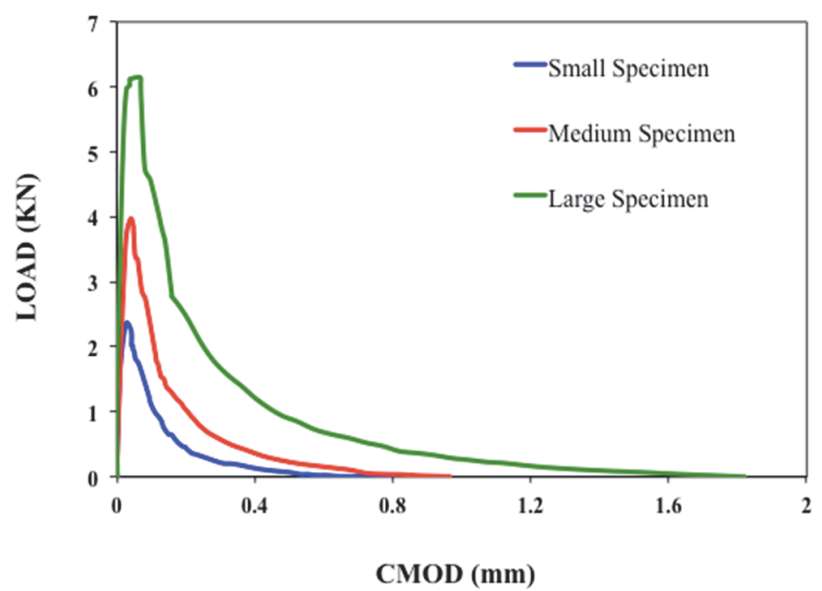

Figure 5: Load-CMOD variations for different beam specimens under static loading

The relative displacements are calculated by monitoring and determining the coordinates of the subsets in the digital images. The DIC set-up consists of a digital camera and a VIC-2D software to analyses the images. During the testing process, the whole specimen is illuminated by providing white light. In order to obtain accurate surface deformation and strain measurements in DIC technique, the specimens are prepared with high contrast speckle pattern. A typical speckle pattern applied on beam specimens has been shown in Fig. 1. Good contrast with the background is achieved by first 
coating the specimens with white paint. Continuous images are taken during the entire experimentation. The underlying principle of correlation software is to recognize and track a specific subset on the series of captured images.

\section{RESULTS AND DISCUSSIONS}

he maximum static load has been recorded for small, medium and large beam specimens as $2.35 \mathrm{kN}, 3.97 \mathrm{kN}$ and $6.15 \mathrm{kN}$, respectively. Variation of recorded load values and corresponding crack mouth opening displacements (CMOD) have been plotted for three beam sizes in Fig. 5. At about $95 \%$ of the peak load, crack initiation has been observed with the final CMOD values of $0.76 \mathrm{~mm}, 0.96 \mathrm{~mm}$ and $1.73 \mathrm{~mm}$ for small, medium and large specimen respectively. During the fatigue test, crack mouth opening displacement values are recorded for every loading and unloading cycles. Typical variation of CMOD with load (Load-CMOD) for selected number of load cycles for medium beam specimen is shown in Fig. 6. Crack propagation for medium size beam has been shown in Fig. 7 in terms of horizontal strains corresponding to percentage of loads. Predictions have been made corresponding to (a) peak load (b) $90 \%$ post peak load (c) $70 \%$ post peak load (d) $50 \%$ post peak load (e) $30 \%$ post peak load and (f) $15 \%$ post peak load. Similar results have been shown in Fig. 8 for beams under fatigue loading. Load displacement variations for selected numbers of load cycles have been presented in Fig. 9. Based on the experimental results critical energy dissipation has been calculated for small, medium and large size beam specimens. The results of critical energy dissipation has been presented in Fig. 10.

\section{Estimation of tip of effective crack}

A method has been proposed in the present study to estimate the tip of effective crack under monotonic and repetitive loading conditions. In this method, the tip of effective crack has been located corresponding to the negligible horizontal displacement jump on either side of crack. During DIC analysis origin is marked at the tip of initial notch. Horizontal displacements fields are obtained corresponding to various reference lines through DIC analysis. Typical variation of horizontal displacement values against distance $(\mathrm{X})$ corresponding to the reference lines, $\mathrm{Y}=4.9,17.17,41.68$ and $49.31 \mathrm{~mm}$ are presented in Fig. 11. In this case, the displacement jump/opening has been calculated corresponding to the peak load with respect to different horizontal crosssections. From Fig. 11, it can be observed that, the tip of the effective crack is located at $49.31 \mathrm{~mm}$ from the notch tip in the case of medium size beam when loaded statically. Further, the size of effective crack length has been estimated to be $26.2 \mathrm{~mm}$ and $98.1 \mathrm{~mm}$ respectively for small and large beams respectively. Similar procedure has been adopted in order to locate the tip of effective crack in medium size concrete beam under fatigue loading. Analysis has been done for $1180^{\text {th }}$ load cycle for medium size beam and the tip has been located at $47.55 \mathrm{~mm}$ beyond the initial notch. For small size beam, an effective crack length of $25.4 \mathrm{~mm}$ has been observed at $200^{\text {th }}$ load cycle. Further, for large size beam the tip of effective crack has been found to be loacated at 102.8 $\mathrm{mm}$ from the initial notch length corresponding to $1395^{\text {th }}$ load cycle.

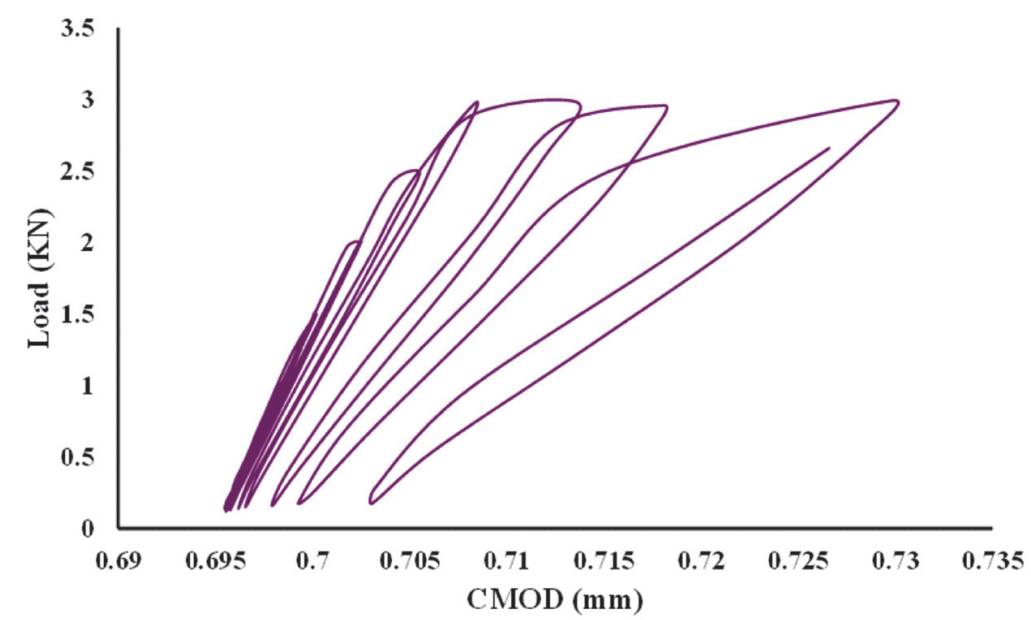

Figure 6: Load-CMOD variation for medium size beam specimen under fatigue loading. 


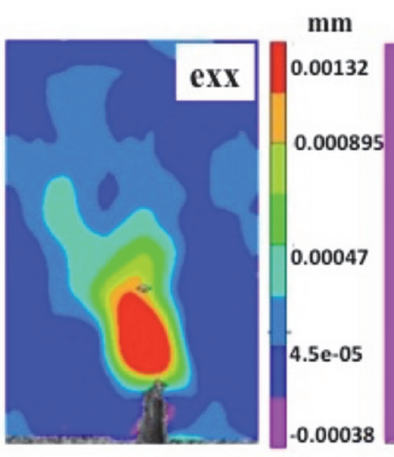

(a)

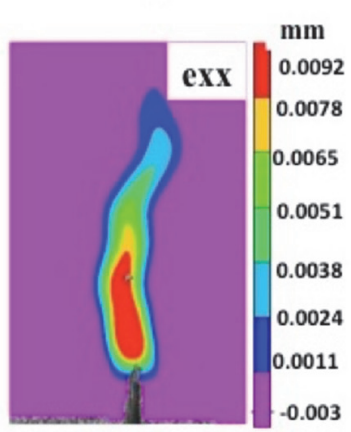

(d)

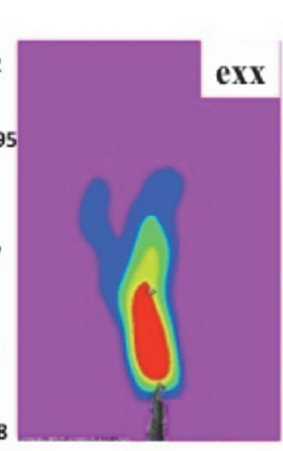

(b)

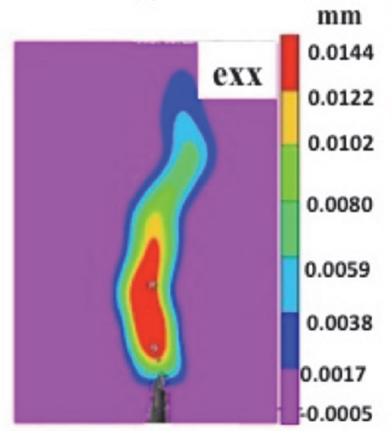

(e)

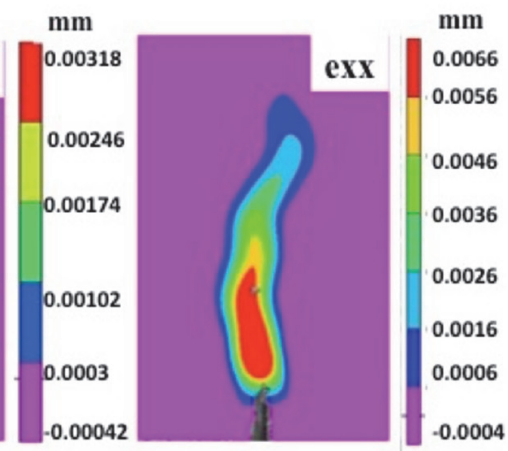

(c)

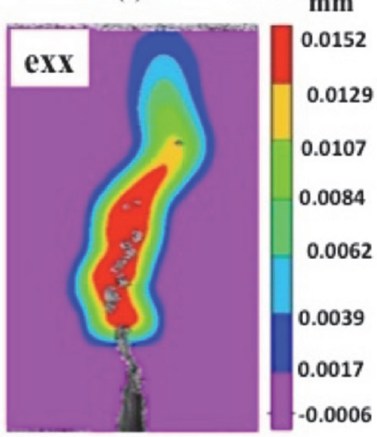

(f)

Figure 7: Horizontal strain contour for medium beam specimen under static loading at (a) peak load (b) $90 \%$ post peak load (c) $70 \%$ post peak load (d) $50 \%$ post peak load (e) $30 \%$ post peak load (f) $15 \%$ post peak load.

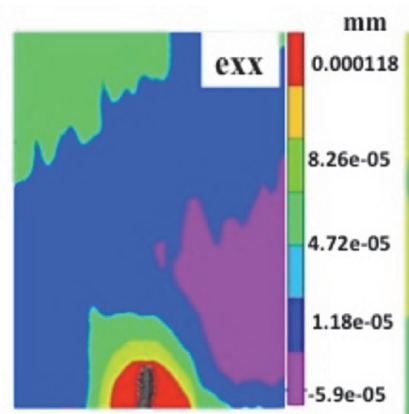

(a)

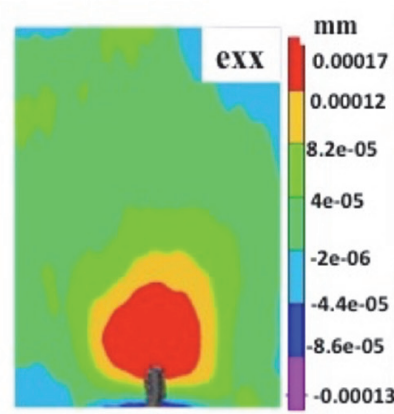

(d)

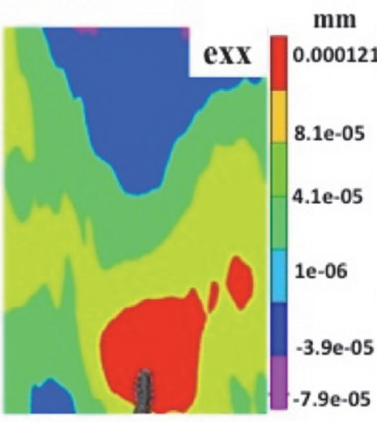

(b)

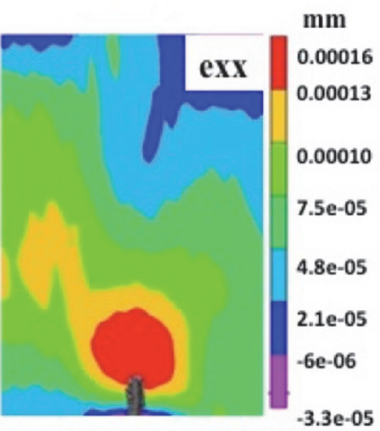

(c)

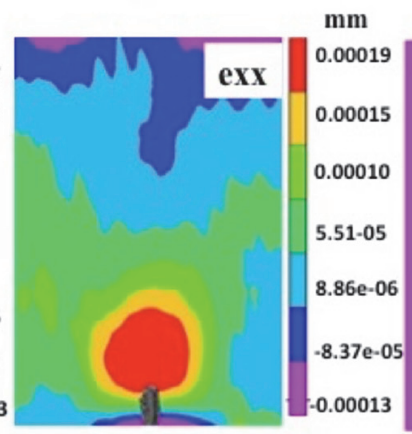

(e)

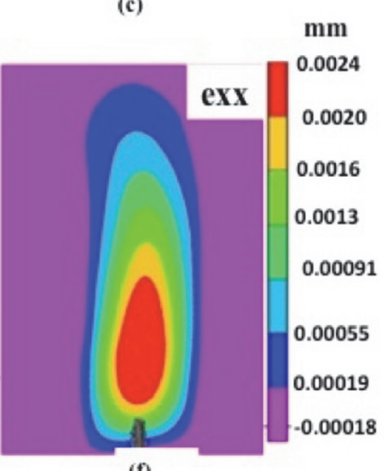

(f)

Figure 8: Horizontal strain contours for medium beam specimen at (a) 300 (b) 600 (c) 800 (d) 1000 (e) 1100 and (f) 1180 th load cycles. 


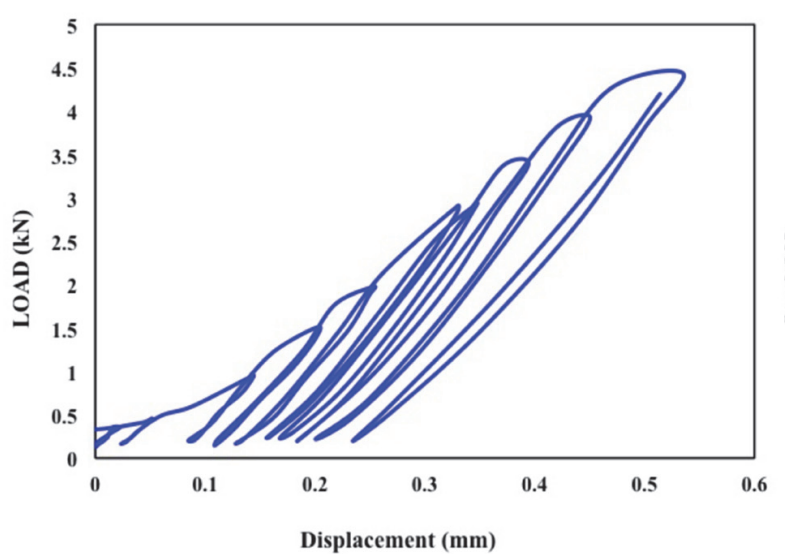

(a)

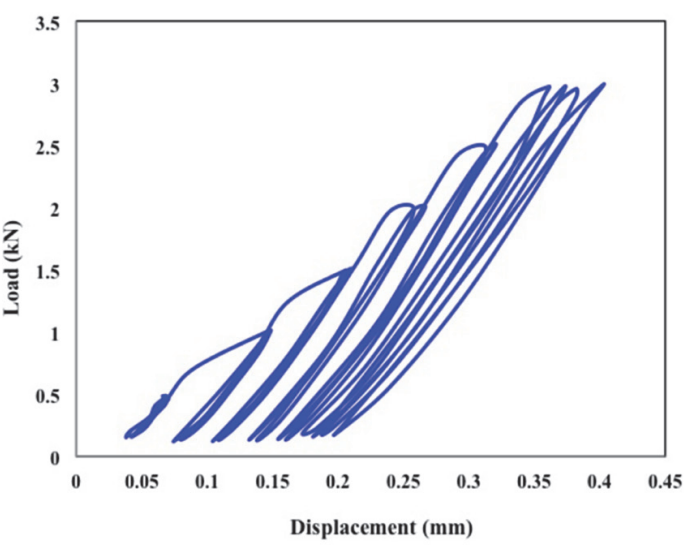

(b)

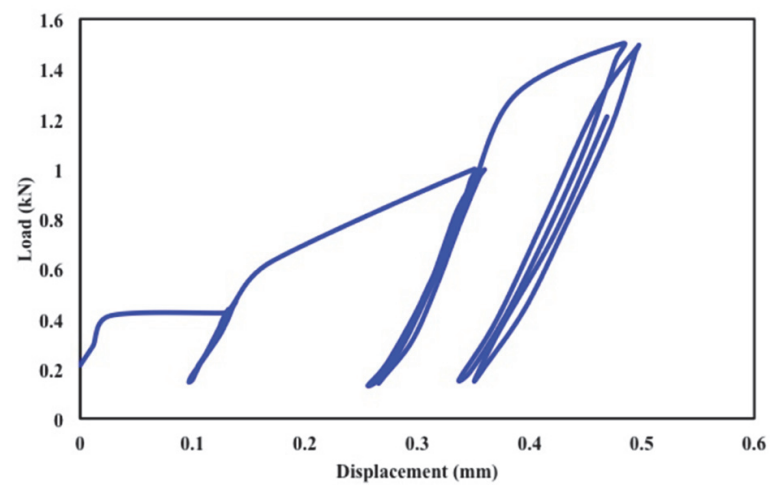

(c)

Figure 9: Load-displacement plots under fatigue loading for (a) large (b) medium and (c) small beam specimens.

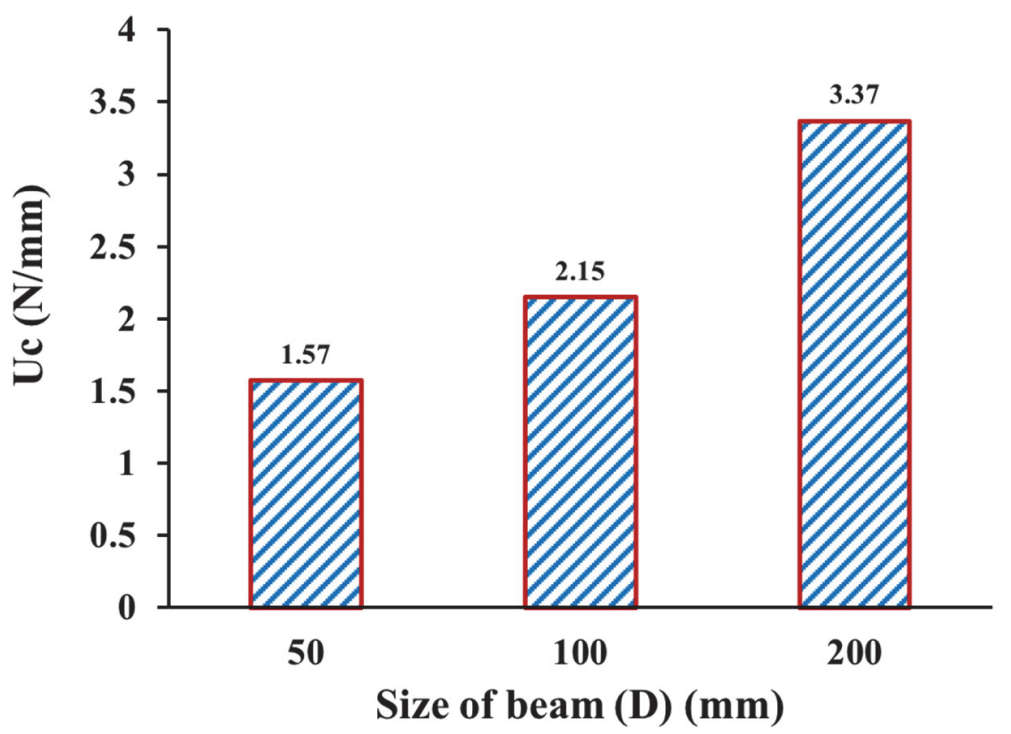

Figure 10: Critical energy dissipation for beam specimens under fatigue loading.

An increase in propagation of crack has been observed in Fig. 7, from peak load to 15\% post peak load. Corresponding to Fig. 7 (a), the effective crack length is expected to be critical and it has been confirmed 
through the DIC analysis procedure. After peak load, an unstable crack growth has been observed through DIC analysis which can be further justified in Figs. 7 (b)-7 (f). Similar observations has been made in Fig. 8(f) in the case of fatigue loading, where the possibility of critical effective crack at $1180^{\text {th }}$ cycle has been confirmed with the calculated value prior to failure.

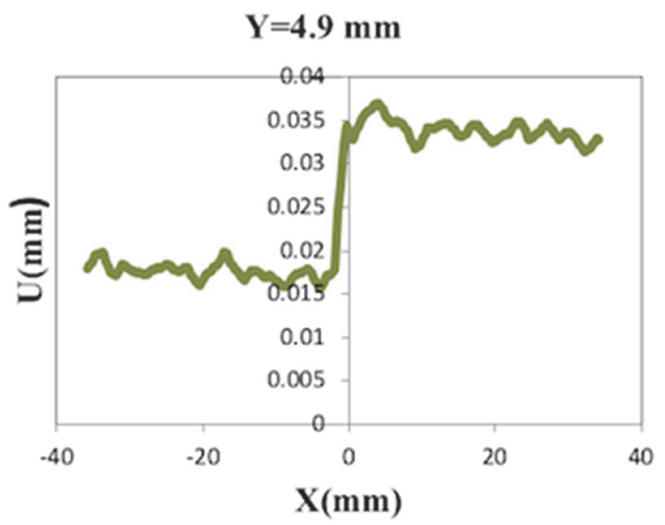

(a)

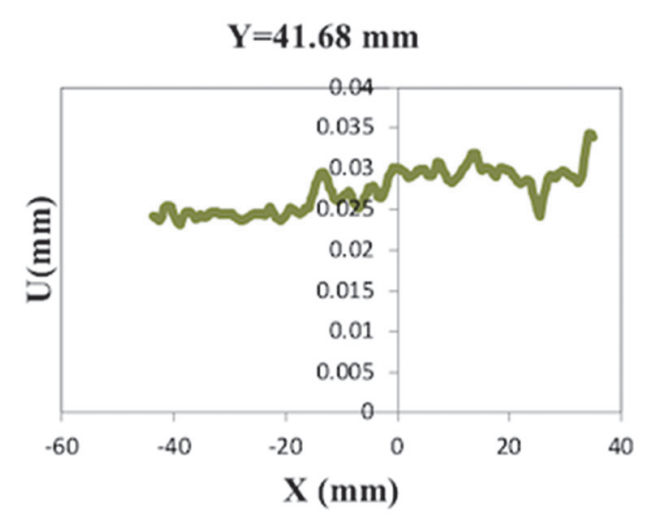

(c)

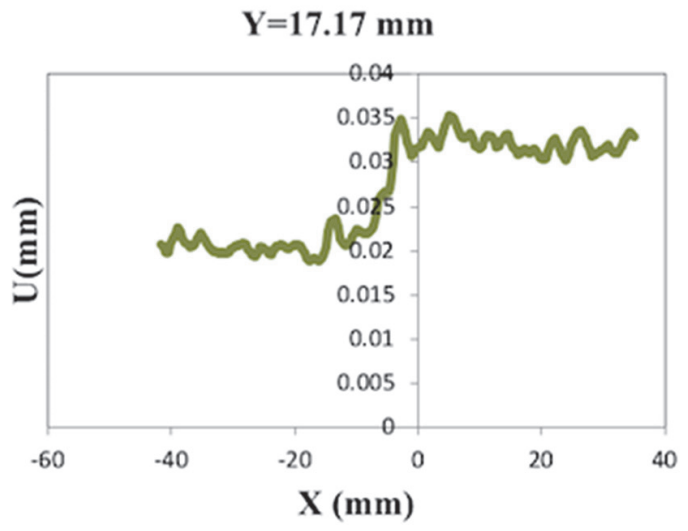

(b)

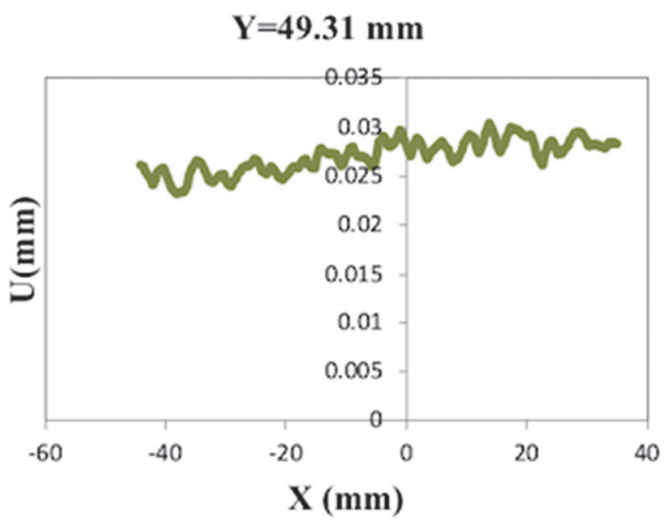

(d)

Figure 11: Displacement profiles at peak load for medium size beam specimen under static loading

\section{$V$ alidation of DIC results}

Accuracy of the results obtained by DIC analysis has been verified in this section. Experimental results of medium beam specimens for both static and fatigue loading cases has been considered for validation study. Vertical displacements below the load point have been obtained through DIC analysis. Images corresponding to peak load, $90 \%$ post peak load, $70 \%$ post peak load, $50 \%$ post peak load, $30 \%$ post peak load and 15\% post peak load has been picked for medium beam specimens under static loading. For specimens under fatigue loading, images have been considered at a interval of 100 cycles. Vertical displacements obtained from DIC analysis have been compared with experimental results at different percentage of post peak load as shown in Fig. 12 for static loading condition. Similarly, for fatigue loading cases vertical displacements obtained from DIC have been compared with experimental results as shown in Fig. 13. A reasonably good agreement can be observed between DIC analysis results and the experimentally recorded values.

\section{Conclusions}

An experimental investigation has been conducted on geometrically similar concrete beam of different sizes in order to understand the fracture processes and fatigue crack growth behaviour of beams under monotonic and fatigue loading. Digital image correlation technique has been adopted in this study. The horizontal displacement jumps are obtained corresponding to various reference lines through DIC analysis. Tip of effective crack has been located where the jump of 
the horizontal displacement is negligible. Critical effective crack length has been obtained for medium size beam specimens under static and fatigue loading cases. Further, an increase in critical energy dissipation has been observed with the increase of the size of the specimen indicating the exhibition of size effect.

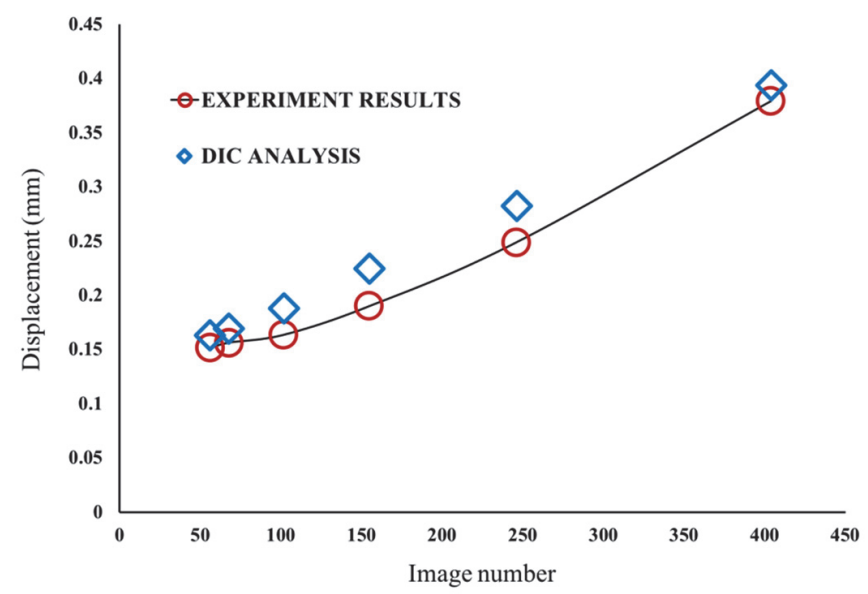

Figure 12: Variation of vertical displacement with different percentage of post peak load.

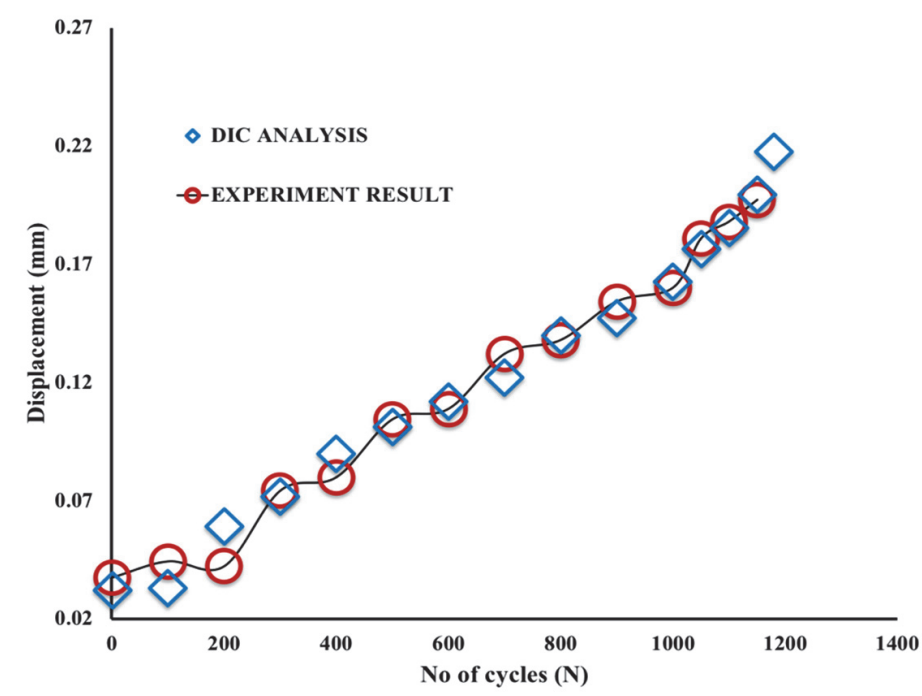

Figure 13: Variation of vertical displacement with number of load cycles.

\section{ACKNOWLEDGEMENT}

he financial grant provided by Department of Science and Technology, New Delhi, India for the execution of the work is greatfully acknowledged.

\section{REFERENCES}

[1] Bhowmik, S. and Ray, S., (2018). An improved crack propagation model for plain concrete under fatigue loading. Engineering Fracture Mechanics, 191, pp.365-382. DOI:10.1016/j.engfracmech.2018.01.003.

[2] Mihashi, H., Nomura, N. and Niiseki, S., (1991). Influence of aggregate size on fracture process zone of concrete detected with three dimensional acoustic emission technique. Cement and Concrete Research, 21(5), pp.737-744. DOI: 10.1016/0008-8846(91)90168-H. 
[3] Zhang, D. and Wu, K., (1999). Fracture process zone of notched three-point-bending concrete beams. Cement and Concrete Research, 29(12), pp.1887-1892. DOI: 10.1016/S0008-8846(99)00186-6.

[4] Tejchman, J., (2010). Calculations of fracture process zones on meso-scale in notched concrete beams subjected to three-point bending. European Journal of Mechanics-A/Solids, 29(4), pp.746-760.

DOI: 10.1016/j.euromechsol.2010.02.008.

[5] Muralidhara, S., Prasad, B.R., Eskandari, H. and Karihaloo, B.L., (2010). Fracture process zone size and true fracture energy of concrete using acoustic emission. Construction and Building Materials, 24(4), pp.479-486.

DOI: $10.1016 /$ j.conbuildmat.2009.10.014.

[6] Saliba, J., Loukili, A., Grondin, F. and Regoin, J.P., (2012). Experimental study of creep-damage coupling in concrete by acoustic emission technique. Materials and structures, 45(9), pp.1389-1401. DOI: 10.1617/s11527-012-9840-3.

[7] Saucedo, L., Rena, C.Y. and Ruiz, G., (2012). Fully-developed FPZ length in quasi-brittle materials. International journal of fracture, 178(1-2), pp.97-112. DOI:10.1007/s10704-012-9769-0.

[8] W. Dong, X. Zhou, and Z. Wu. (2013). On fracture process zone and crack extension resistance of concrete based on initial fracture toughness. Construction and Building Materials, 49, pp. 352- 363. DOI: $10.1016 /$ j.conbuildmat.2013.08.041.

[9] Sagar, R.V., Prasad, R.V., Prasad, B.R. and Rao, M.V.M.S., (2013). Microcracking and fracture process in cement mortar and concrete: A comparative study using acoustic emission technique. Experimental Mechanics, 53(7), pp.1161-1175. DOI:10.1007/s11340-012-9708-z.

[10] Saliba, J., Loukili, A., Grondin, F. and Regoin, J.P., (2014). Identification of damage mechanisms in concrete under high level creep by the acoustic emission technique. Materials and structures, 47(6), pp.1041-1053. DOI: $10.1617 /$ s11527-013-0113-6.

[11] Saliba, J., Loukili, A. and Grondin, F., (2015). Acoustic emission monitoring and quantitative evaluation of damage in concrete beams under creep. In Acoustic Emission and Related Non-Destructive Evaluation Techniques in the Fracture Mechanics of Concrete (pp. 113-136). DOI:10.1016/B978-1-78242-327-0.00006-4.

[12] Saliba, J., Matallah, M., Loukili, A., Regoin, J.P., Grégoire, D., Verdon, L. and Pijaudier-Cabot, G., (2016). Experimental and numerical analysis of crack evolution in concrete through acoustic emission technique and mesoscale modelling. Engineering Fracture Mechanics, 167, pp.123-137. DOI:10.1016/j.engfracmech.2016.03.044.

[13] Li, J. and Wu, C., (2018). Damage evaluation of ultra-high performance concrete columns after blast loads. International Journal of Protective Structures, 9(1), pp.44-64. DOI:10.1177/2041419617743986.

[14] Wu, Z., Rong, H., Zheng, J., Xu, F. and Dong, W., (2011). An experimental investigation on the FPZ properties in concrete using digital image correlation technique. Engineering Fracture Mechanics, 78(17), pp.2978-2990. DOI:10.1016/j.engfracmech.2011.08.016.

[15] Skarzynkki, L. and Tejchman, J., (2013). Experimental investigations of fracture process using DIC in plain and reinforced concrete beams under bending. Strain, 49(6), pp.521-543. DOI:10.1111/str.12064.

[16] Ohno, K., Uji, K., Ueno, A. and Ohtsu, M., (2014). Fracture process zone in notched concrete beam under threepoint bending by acoustic emission. Construction and building materials, 67, pp.139-145.

DOI: $10.1016 /$ j.conbuildmat.2014.05.012.

[17] Alam, S.Y., Saliba, J. and Loukili, A., (2013). Study of evolution of fracture process zone in concrete by simultaneous application of digital image correlation and acoustic emission. In VIII International Conference on Fracture Mechanics of Concrete and Concrete Structures (pp. 1-9).

[18] Alam, S.Y., Saliba, J. and Loukili, A., (2014). Fracture examination in concrete through combined digital image correlation and acoustic emission techniques. Construction and Building Materials, 69, pp.232-242. DOI :10.1016/j.conbuildmat.2014.07.044.

[19] Alam, S.Y., Loukili, A., Grondin, F. and Rozière, E., (2015). Use of the digital image correlation and acoustic emission technique to study the effect of structural size on cracking of reinforced concrete. Engineering Fracture Mechanics, 143, pp.17-31. DOI:10.1016/j.engfracmech.2015.06.038.

[20] Trivedi, N., Singh, R.K. and Chattopadhyay, J., (2015). Investigation on fracture parameters of concrete through optical crack profile and size effect studies. Engineering Fracture Mechanics, 147, pp.119-139.

DOI: $10.1016 /$ j.engfracmech.2015.08.027.

[21] Xie, Z.L., Zhou, H.F., Lu, L.J. and Chen, Z.A., (2017). An investigation into fracture behavior of geopolymer concrete with digital image correlation technique. Construction and Building Materials, 155, pp.371-380. DOI: 10.1016/j.conbuildmat.2017.08.041 